\title{
Mitral Valve Replacement Using Subvalvular Apparatus: A Systematic Review and Meta-Analysis
}

\author{
Wan Chin Hsieh, MD, ${ }^{1,2}$ Anas Aboud, MD, ${ }^{3}$ Brandon Michael Henry, MD,${ }^{4}$ Chung Dann Kan, MD, PhD, \\ Mohamed Omara, MD, ${ }^{6}$ Jaroslav Lindner, $\mathrm{MD}, \mathrm{PhD}^{2}$ \\ ${ }^{1}$ First Faculty of Medicine, Charles University, Prague, Czech Republic; ${ }^{2} 2$ nd Department of Cardiovascular Surgery, First Faculty \\ of Medicine, Charles University and General University Hospital in Prague, Prague, Czech Republic; ${ }^{3}$ Department of Cardiac \\ and Thoracic Vascular Surgery, University of Schleswig-Holstein, Lübeck Campus, Lübeck, Germany; ${ }^{4}$ Division of Cardiology, \\ Cincinnati Children's Hospital Medical Center, Cincinnati, Ohio, USA; ${ }^{5}$ Division of Cardiovascular Surgery, Department of Surgery, \\ National Cheng Kung University Hospital, Tainan, Taiwan; ${ }^{6}$ Department of Thoracic and Cardiovascular Surgery, Research Institute, \\ Cleveland Clinic, Cleveland, Ohio, USA
}

\section{ABSTRACT}

Background: To assess clinical outcomes among participants undergoing mitral valve replacement with preservation of subvalvular apparatus.

Methods: Electronic databases, including PubMed, Embase, Science Direct, World of Science, Scopus, Biosis, SciElo and Cochrane library, were probed using an extensive search strategy. Studies that reported at least one clinical outcome, such as morbidity, mortality, early 30-day mortality, myocardial failure, survival, late cerebrovascular events, length of stay, or major operative complications (stroke, prolonged ventilation, and reoperation for bleeding, renal failure, and sternal infection) were considered for inclusion. Data was extracted and pooled into a meta-analysis in RevMan (version 5.3) using a random-effects model.

Results: A total of 21 studies with 5,106 participants (age range: 27.3-69.2 years) were included in this meta-analysis. Preservation of the subvalvular apparatus during MVR significantly reduces the risk of long-term mortality (OR: 0.46; 95\% CI: 0.33-0.64), but not early mortality (OR: 0.76; $95 \%$ CI: 0.12-4.93). No significant difference ejection fraction was observed (SMD: 0.10; 95\% CI: -0.44-0.64). Similarly, there was no significant difference in the risk of stroke, renal failure, and pneumonia between C-MVR and in the control group.

Conclusion: MVR with the preservation of subvalvular apparatus improves clinical outcomes, such as long-term mortality, hospital length of stay, pneumonia, and bleeding. There is no significant difference in the risk of stroke, renal failure, or ICU length of stay. However, there is very limited data available with respect to bleeding, sepsis, and nosocomial infections.

Received fuly 7, 2019; received in revised form fanuary 27, 2020; accepted fanuary 28, 2020.

Correspondence: Wan Chin Hsieh, MD, 2nd Department of Cardiovascular Surgery, First Faculty of Medicine, Charles University and General University Hospital in Prague, U Nemocnice 499/2, 12800 Praba 2-Nové Město, Prague, Czech Republic; (e-mail: dr.hsieb520@gmail.com).

\section{INTRODUCTION}

The prevalence of ischemic mitral regurgitation ranges between 1.6 million to 2.8 million in the United States. Patients with mild or greater degrees of mitral regurgitation after myocardial infarction are at a significantly increased risk of mortality [Rossi 2017; Grigioni 2001; Ellis 2002]. A majority of these patients require mitral valve replacement (MVR) when a repair is not feasible, however, this process can result in a deterioration in the left ventricular (LV) function. As such, preservation of optimal LV function is of great significance in this group of patients [Ellis 2002].

The importance of preserving the subvalvular apparatus was first demonstrated in the early 1960s [Lillehei 1963]. Studies published in the late 1970s reported that the preservation of subvalvular valve apparatus improves $L V$ function and mortality, especially in patients with mitral regurgitation [Hüseyin 2013]. Many studies have been addressed the early and late hemodynamic benefits of preserving the mitral subvalvular apparatus during MVR, however, the issue of complete versus partial chordal preservation has yet to be fully investigated [Yun 2002].

Similarly, in non-rheumatic MVR, preservation of the subvalvular apparatus has maintained annular-papillary continuity, which helps improve LV function in the early and late postoperative period, and subsequently showed shortand long-term survival [Coutinho 2015]. It also has been suggested that MVR with preservation of subvalvular apparatus provides better freedom from mild to moderate mitral regurgitation (MR) in patients with ischemic mitral regurgitation (IMR), with a low incidence of valve-related complications. A study conducted by Reece et al [Reece 2004] reported that mitral valve repair is superior to replacement. However, recent literature suggests that MVR with preservation of the subvalvular apparatus still is a better option in some patients with ischemic mitral regurgitation. In this study, we aimed to assess the clinical outcomes of MVR with complete preservation of subvalvular apparatus as compared with other procedures. 
Table 1. Assessment of eligibility by full texts, according to the eligibility criteria

\begin{tabular}{|c|c|}
\hline Population & $\begin{array}{l}\text { Patients undergoing mitral valve replacement. Animal } \\
\text { studies excluded }\end{array}$ \\
\hline Intervention & MVR with complete preservation of subvalvular apparatus \\
\hline Comparator & $\begin{array}{l}\text { Partial preservation (the posterior leaflet or basal chor- } \\
\text { dae), mitral repair, excision of subvalvular apparatus, or } \\
\text { comparison between partial or complete preservation }\end{array}$ \\
\hline Outcomes & $\begin{array}{c}\text { Primary outcome: mortality (30 day, and long-term } \\
\text { mortality), ejection fraction }\end{array}$ \\
\hline $\begin{array}{l}\text { Secondary } \\
\text { outcome }\end{array}$ & $\begin{array}{l}\text { Hospital length of stay, ICU length of stay, stroke, } \\
\text { prolonged ventilation, bleeding, renal failure, infection, } \\
\text { pulmonary complication (pneumonia, atelectasis, and } \\
\text { prolonged ventilation), postoperative need for positive } \\
\text { inotropic agents, postoperative complications }\end{array}$ \\
\hline Study design & $\begin{array}{l}\text { Randomised controlled trials, observational studies. Case } \\
\text { reports and case series were excluded }\end{array}$ \\
\hline $\begin{array}{l}\text { Publication } \\
\text { type }\end{array}$ & Reviews, editorials, comments and letters were excluded \\
\hline Language & Any language \\
\hline
\end{tabular}

\section{METHODS}

Search strategy and study selection: A search of the electronic databases, including PubMed, Embase, Science Direct, World of Science, Scopus, Biosis, SciELO, Cochrane Library, and China National Knowledge Infrastructure (CNKI) database using an extensive search strategy to identify potentially relevant articles. Moreover, the bibliographies and citation sections (i.e, snowballing technique) of the included articles also were searched to identify any additional studies. No language or date restrictions were applied to the searches.

The following steps were conducted during study selection process: (1) identification of titles of records identified through databases searching, (2) removal of duplicates, (3) screening by titles and abstracts, (4) assessment of eligibility by full-texts according to the eligibility criteria explained in Table 1, and (5) finally inclusion. This process was carried out by two independent reviewers; in the case of any disagreement, a consensus was reached by consolation with a third reviewer.

Search strategy:

1. "mitral valve"[MeSH Terms] OR ("mitral"[All Fields] AND "valve"[All Fields]) OR "mitral valve"[All Fields]

2. "heart valves"[MeSH Terms]

3. "chordae tendineae"[MeSH Terms] OR ("chordae"[All Fields] AND "tendineae"[All Fields]) OR "chordae tendineae"[All Fields]

4. atrioventricular[All Fields] AND valve[All Fields]

5. \#1 OR \#2 OR \#3 OR \#4

6. "replantation"[MeSH Terms]

7. "surgery"[Subheading] OR "surgical procedures, operative"[MeSH Terms] OR "general surgery"[MeSH Terms] OR surgery[Text Word]

8. \#6 OR \#7

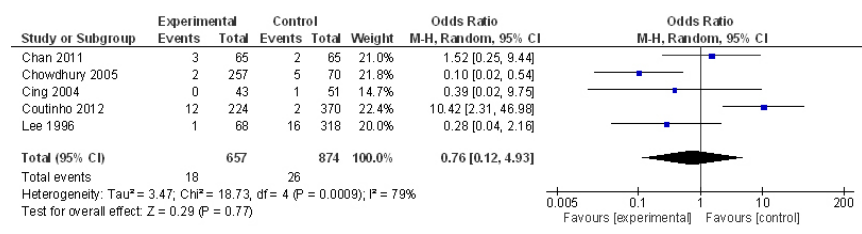

Figure 1. Early mortality (30-day mortality)

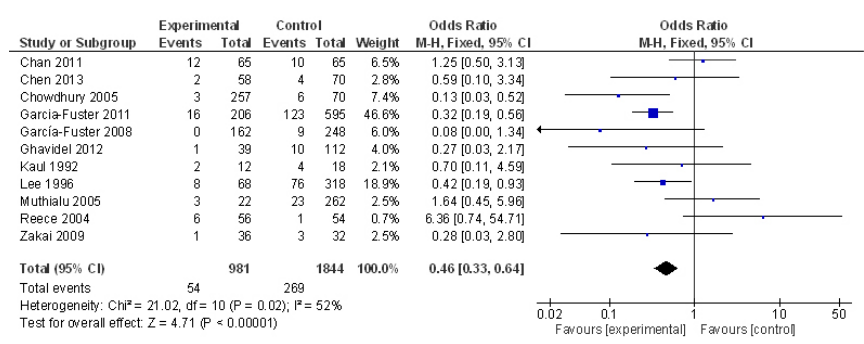

Figure 2. Long-term mortality

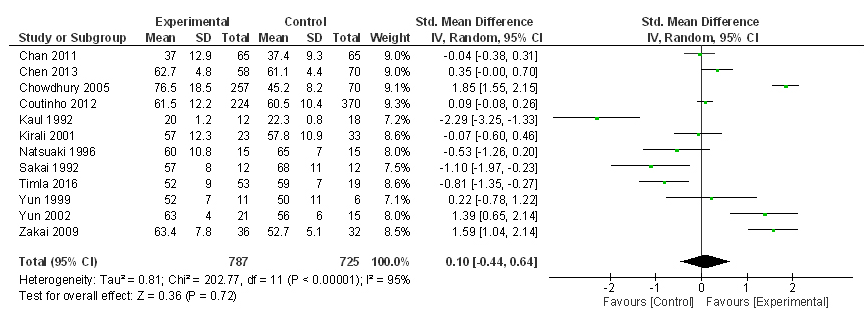

Figure 3. Ejection fraction

9. subvalvular[All Fields]

AND

("instrumentation"[Subheading]

OR

"instrumentation"[All Fields] OR "apparatus"[All Fields])

10. ("mitral valve"[MeSH Terms] OR ("mitral"[All Fields] AND "valve"[All Fields]) OR "mitral valve"[All Fields]) AND ("instrumentation"[Subheading] OR "instrumentation"[All Fields] OR "apparatus"[All Fields])

11. \#9 OR \#10

12. Preserv* $[$ All Fields $]$

13. \#5 AND \#8

14. \#11 AND \#12

15. \#13 AND \#14

Eligibility criteria: Studies that (1) included patients undergoing MVR with preservation of subvalvular apparatus and (2) reported at least one clinical outcome such as morbidity, mortality, early 30-day mortality, myocardial failure, survival, late cerebrovascular events, length of stay, major operative complications (stroke, prolonged ventilation, and reoperation for bleeding, renal failure, and sternal infection) were considered for inclusion in the review (Table 1).

Data extraction: Data from the eligible studies were extracted in a predesigned extraction spreadsheet by two independent reviewers. Any disagreements were resolved by a consensus among the reviewers. From each study, patient 


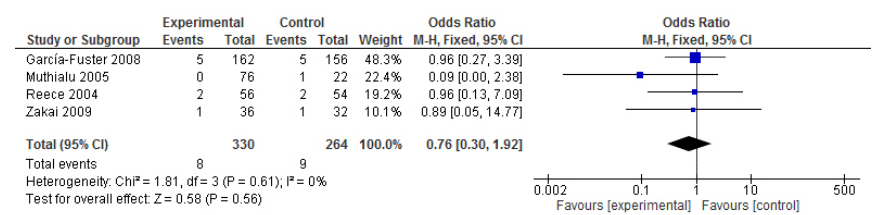

Figure 4. Stroke

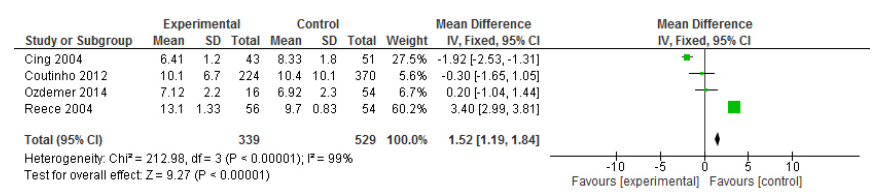

Figure 5. Hospital length of stay

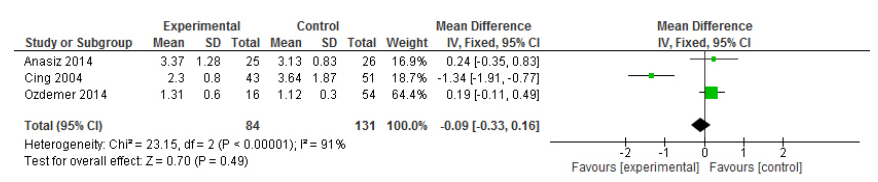

Figure 6. ICU length of stay

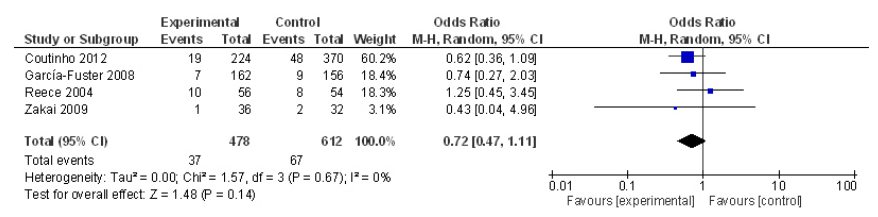

Figure 7. Renal failure

demographics and characteristics, study design, country, and outcomes (number of events and number of total groups) were extracted.

Definitions of outcomes

1. Primary outcomes

Early mortality: Number of deaths within 30 days of the post-operative period (dichotomous data) [Osswald 1999]

Long term mortality: Number of deaths at follow up (dichotomous data)

Ejection fraction: Measurement of how much blood the left ventricle pumps out with each contraction (continuous data measured using Echocardiogram)

2. Secondary outcomes

Hospital length of stay: Number of days spent in hospital pre- and post-MVR (continuous data)

Intensive care unit stay: Number of days spent in intensive care unit post-MVR (continuous data)

Stroke: Rapidly developing clinical signs of focal (or global) disturbance of cerebral function, lasting more than 24 hours or leading to death, with no apparent cause other than that of vascular origin (The global burden of cerebrovascular disease (dichotomous data).

Bleeding: Timing of events, according to the clinical trial and according to the particular pharmacotherapy or intervention being studied, but at least at seven days, 30 days, and/or at the end of the trial (dichotomous data).

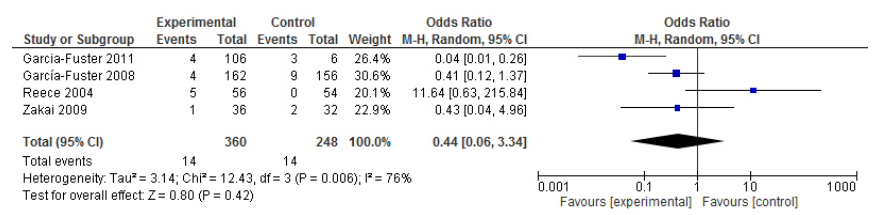

Figure 8. Pneumonia

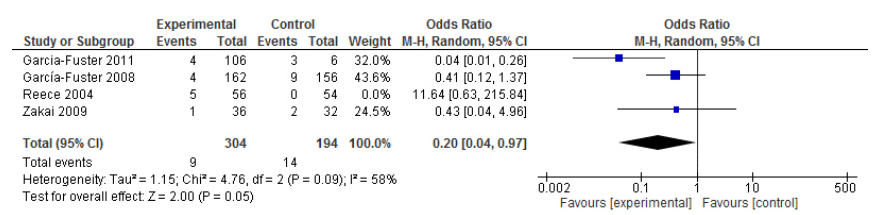

Figure 9. Pneumonia (Subgroup analysis)

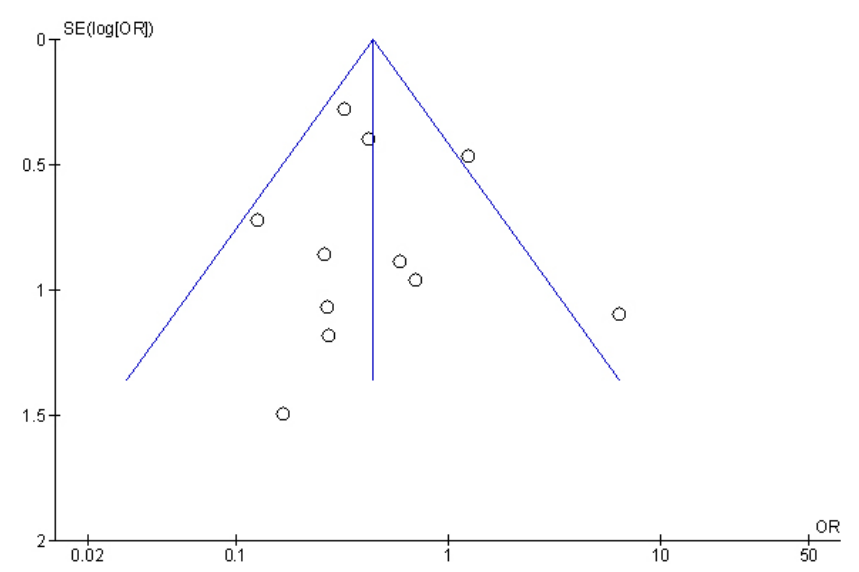

Figure 10. Publication bias analysis by funnel plot graphic

Renal failure: Abrupt loss of kidney function assessed using Serum creatinine (acute kidney injury (acute renal failure) (dichotomous data)

Sternal infection: Positive culture results from surgical sites or drainage from the mediastinal area or evidence of infection during surgical re-exploration or fever, sternal instability, and positive blood culture result (dichotomous data) [Cotogni 2015].

- Postoperative need for positive inotropic agents: Patients receiving any inotrope/vasopressor postoperatively up to 12 hours after skin closure, including any agents initiated intraoperatively (dichotomous data) [Williams 2011]

- Nosocomia infection: Infection occurring 48 hours after hospital admission (dichotomous data) [Kouchak 2012]

- Pulmonary complication: Complications such as pneumonia, atelectasis, and prolonged ventilation (dichotomous data)

- Postoperative complications: Any other postoperative complications except the above-mentioned items (dichotomous data)

Statistical analysis: Demographic details were summarised using descriptive statistics. If the data was homogenous, a 
Table 2. [add title]

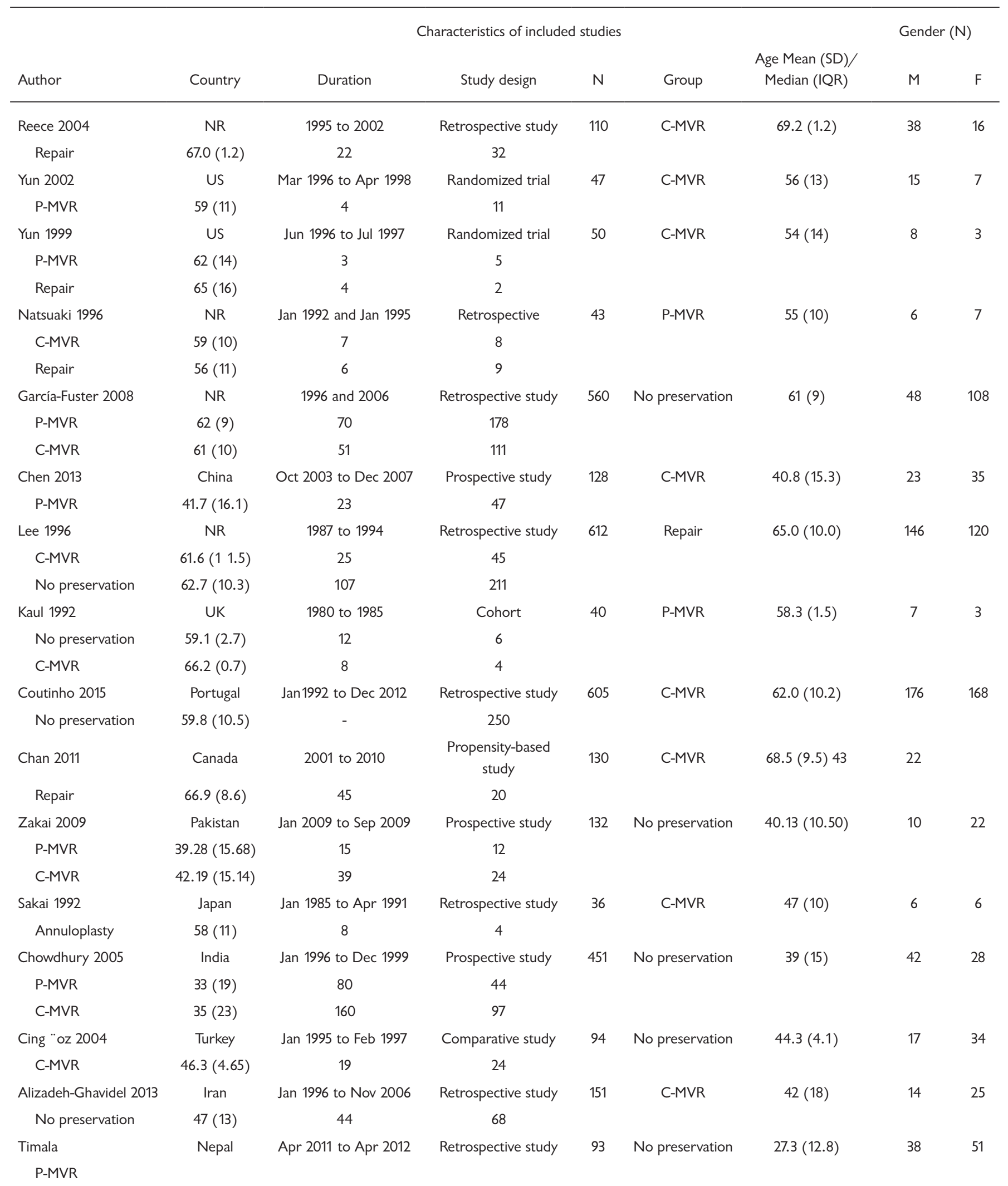


Table 2. [add title]

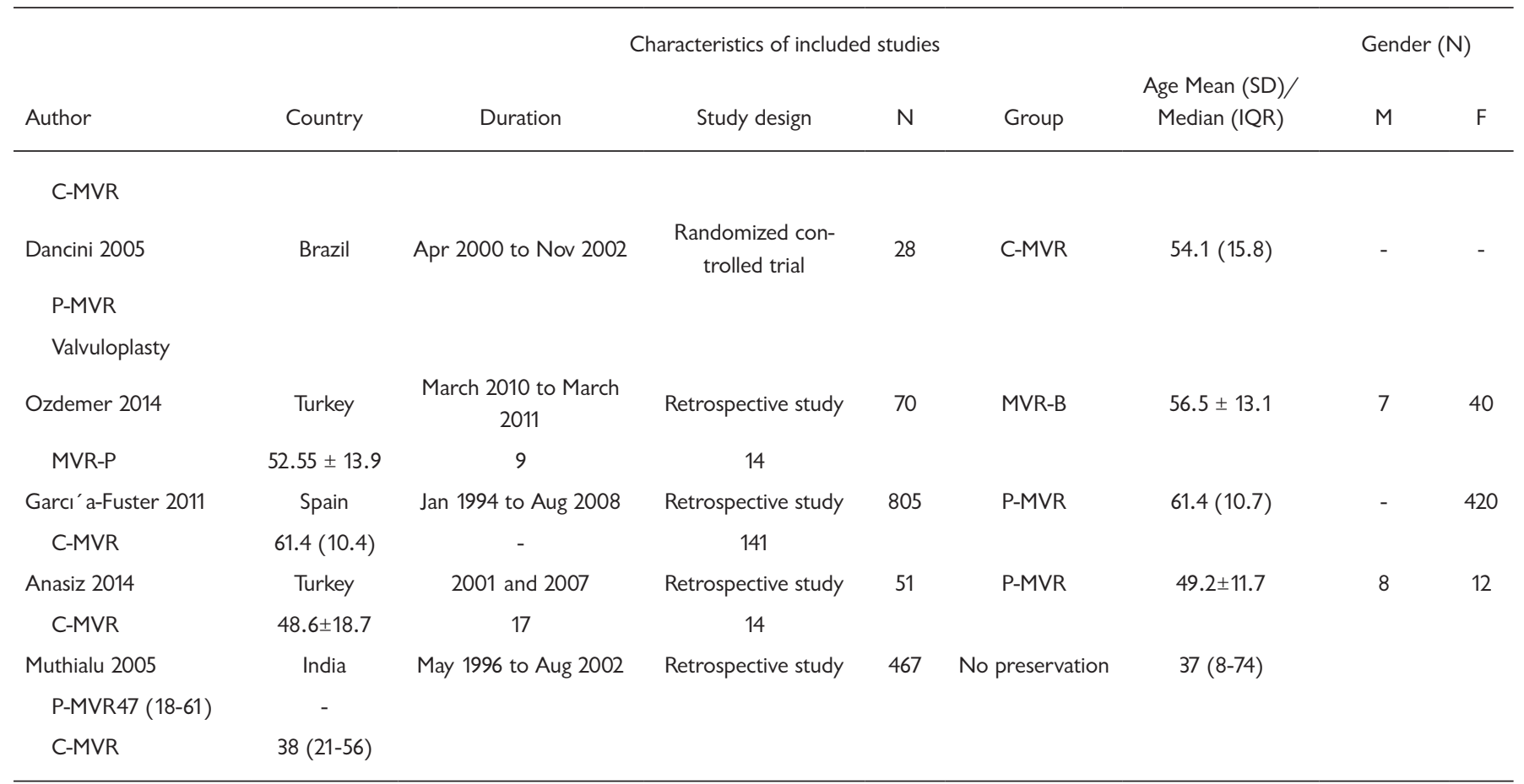

C-MVR: complete preservation of subvalvular apparatus; P-MVR: Partial preservation of subvalvular apparatus; US: United states; UK; United Kingdom; NR: Not reported

meta-analysis was performed. Forest plots were generated for graphical presentations of clinical outcomes. Meta-analysis was conducted using a weighted DerSimonian-Laird random-effects model with effect sizes of odds ratio (OR), standardised mean difference (SMD) with $95 \%$ confidence interval (CI). This model was weighted by the number of events in each study. All statistical tests were two-sided, with $P<.05$ being considered statistically significant, except if otherwise specified. Publication bias was assessed using visual inspection of funnel plots. To assess potential heterogeneity among the included studies, the $\mathrm{I}^{2}$ statistic was employed with a value $>50 \%$ considered as a measure of significant heterogeneity. The meta-analysis was conducted using "RevMan version 5.3" (from Cochrane community). If a meta-analysis was not feasible, the findings of the systematic review were described.

\section{RESULTS}

The literature searches identified 254 records, with five additional records added from the reference search. After removal of duplicates, there were 255 citations, which were screened using title and abstracts. A total of 55 articles were considered potentially relevant, based on the initial screening, and the full text of the articles were evaluated. However, further to researching the full text of the articles, 12 could not be retrieved, thus being discarded; moreover, following an analysis of the full-text against the exclusion criteria in the methods section, 22 articles were excluded for the following reasons: One study was focused on a microsimulation; one article was a commentary of another study; in one study there was no comparator; in 15 articles there were no preservation of the subvalvular apparatus; and four studies did not have data on the relevant clinical outcome measures investigated. Finally, 21 studies (5,106 participants) were included in the meta-analysis. The mean age of the study samples ranged between 27.3 and 69.2 years. Of the 21 included studies, three were randomized studies, 15 were observational studies, and three did not report a study design. The included studies inclusively compared complete preservation of subvalvular apparatus during MVR (C-MVR) with no preservation ( $\mathrm{N}=10$ studies), partial preservation of subvalvular apparatus (P-MVR) $(\mathrm{N}=12$ studies), mitral valve repair $(\mathrm{N}=5$ studies), and annuloplasty ( $\mathrm{N}=2$ studies). Most of the patients had undergone MVR for rheumatic disease, or chronic mitral regurgitation. Detailed study characteristics are presented in Table 2.

Primary outcomes: Early mortality (30-day mortality). Early mortality was reported in five studies [Coutinho 2015; Chan 2011; Chowdhury 2005; Cingöz 2004; Lee 1996]. A metaanalysis these studies evaluating the effect on early mortality reported no significant difference between C-MVR and control groups (OR 0.76; 95\% CI 0.12 to $\left.4.93 ; P=.77 ; \mathrm{I}^{2}=79 \%\right)$.

Long term mortality: A total of 11 studies $(\mathrm{N}=2825)$ reported data for a late mortality outcome [Reece 2004; Chan 2011; Chowdhury 2005; Lee 1996; Chen 2013; García-Fuster 
2008; García-Fuster 2011; Alizadeh-Ghavidel 2013; Kaul 1992; Zakai 2009; Muthialu 2005]. A meta-analysis of these studies revealed that preservation of subvalvular apparatus during MVR significantly reduces the risk of long term mortality (odds ratio [OR] $0.46 ; 95 \%$ confidence interval [CI] 0.33 to $0.64 ; P<.00001 ; \mathrm{I}^{2}=52 \%$ ) when compared to control procedure.

Ejection fraction (EF): Data on EF was reported in 11 studies ( $N=1512$ ) [Yun 2002; Coutinho 2015; Chan 2011; Chowdhury 2005; Chen 2013; Kaul 1992; Zakai 2009; Natsuaki 1996; Sakai 1992; Timala 2016; Yun 1999]. A pooled summary estimate of these 11 studies found no significant difference in EF between C-MVR and no preservation or partial preservation (standard mean difference [SMD]: 0.10; 95\% CI: -0.44 to $\left.0.64 ; P=.72 ; \mathrm{I}^{2}=95 \%\right)$.

Secondary outcomes: Stroke. Incidence of stroke was reported in only four studies [Reece 2004; García-Fuster 2008; Zakai 2009; Muthialu 2005]. A pooled analysis found that there was no significant difference in stroke between C-MVR and the control group (OR: 0.76 ; 95\% CI: 0.30 to $\left.1.92 ; P=.56 ; \mathrm{I}^{2}=0 \%\right)$.

Hospital length of stay (LOS): Four studies compared hospital LOS in C-MVR versus control group [Coutinho 2015; Reece 2004; Cingöz 2004; Ozdemir 2014]. A meta-analysis of these studies found a significant difference in hospital LOS between C-MVR and control group (mean difference [MD]: 1.52 days; $95 \%$ CI: 1.19 to $1.84 ; P=<.00001 ; \mathrm{I}^{2}=99 \%$ ).

ICU length of stay: Three studies assessed ICU length of stay. Pooling revealed there was no significant difference between C-MVR with subvalvular preservation when compared with no preservation (MD: -009 days; 95\% CI: -0.33 to 0.16$)$.

Renal failure: Four studies assessed renal failure among participants undergoing MVR with the preservation of subvalvular apparatus. Summary estimate of these four studies showed slight, but not statistically significant reduction in renal failure in C-MVR group compared with no preservation or partial preservation (OR: $0.72 ; 95 \%$ CI: 0.47 to 1.11 ; $\left.P=.14 ; \mathrm{I}^{2}=0.0 \%\right)$.

Pneumonia: Four studies assessed the effect of C-MVR on the risk of pneumonia [Reece 2004; García-Fuster 2008; García-Fuster 2011; Zakai 2009]. Pooled analysis of these studies demonstrated no significant difference in the risk of pneumonia (OR $0.44 ; 95 \%$ CI 0.06 to $3.34 ; P=.12 ; I^{2}=76 \%$ ). However, when we did sensitivity analysis by removing Reece 2004 study, results were favorable to the C-MVR group (OR $0.20 ; 95 \%$ CI 0.04 to $0.97 ; P=.05 ; \mathrm{I}^{2}=58 \%$ ).

Other outcomes: Two studies [Reece 2004; Zakai 2009] reported eight nosocomial infections in the MVR group and five studies in repair, one study in no subvalvular preservation group, and two in partial MVR.

Prolonged ventilation was reported more in no subvalvular preservation group $(12.5 \% ; \mathrm{N}=32)$ and one in $\mathrm{C}-\mathrm{MVR}$ group $(2.7 \% ; \mathrm{N}=36)$.

Similarly, in two studies [Coutinho 2015; García-Fuster 2011], bleeding was observed less in the MVR group than no subvalvular preservation group (9 versus 33 ). The study by García-Fuster in 2008 reported that sepsis was observed more in partial MVR (five cases) than in no subvalvular preservation (two cases) and C-MVR (one case).

\section{DISCUSSION}

All mitral valve components such as the annulus, leaflets, chordae tendinae, and papillary muscles work in coordination to facilitate normal valvular function [Miller 2004; Kodavatiganti 2002; Condado 2003]. The mitral valve consists of two papillary muscles, the anterolateral, and the posteromedial [Piérard 2004]. Mitral regurgitation is a condition that results from disruption of the valve leaflets or any of the abovementioned components of the mitral apparatus [Maganti 2010].

In the early 1960 s, MVR was carried out to manage conditions like mitral regulations by implantation of a Starr-Edwards prosthetic valve, with complete removal of the mitral leaflets, the heads of the papillary muscles, and chordae tendinae [Starr 1961]. However, this procedure was associated with a high incidence of low cardiac output syndrome, other morbidity, and mortality. Too reduce such complications, a subvalvular apparatus preservation (SVP) strategy was introduced [Athanasiou 2008]. David et al, in 1983, revised the process of MVR with the preservation of the chordae tendineae [David 1983]. Convincing clinical evidence was reported in favor of the preservation of papillary muscles in the study by Lillehei et al [Lillehei 1964].

Findings from this meta-analysis indicate that both the risk of mortality and pneumonia were found to be reduced in the C-MVR group as compared with the control group. It was observed that C-MVR reduced ICU length of stay, and bleeding as compared with the control group. One study reported that prolonged ventilation was reduced in C-MVR group compared to no preservation.

Although the results of our analysis on long-term mortality were in favor of C-MVR, no statistically significant difference was observed for 30-day mortality between the experimental and control groups. A previous meta-analysis conducted by Athanasiou et al reported that excision of the subvalvular apparatus was found to be significantly associated with an increased risk of overall mortality and 30-day perioperative mortality [Athanasiou 2008]. In left ventricular contraction, the papillary muscles play a vital role by drawing the mitral ring toward the apex to shorten the axis for the ejection of blood [Solomon 2006]. Hence, preserving subvalvular apparatus during MVR may improve the ejection fraction, thereby reducing mortality.

The risk of stroke, renal failure, and pneumonia were slightly on the lower side in the C-MVR group than in control group. However, the results were not statistically significant.

Strengths and limitations: A few limitations of this metaanalysis should be considered. First, most of the included studies were single-center retrospective observational studies, which are a high risk for inherent biases, such as recall bias. Second, while inspection of funnel plots indicated a fairly symmetrical distribution, the possibility of such bias still exists and should be considered when interpreting this study's findings. Third, substantial statistical heterogeneity was present, 
but we were not able to explore the sources due to the low number of studies included in each analysis. However, we suspect that the main source of heterogeneity was the different comparators employed for the control group. Very limited data was available with respect to bleeding, sepsis, ionotropic usage, and nosocomial infections, as such, there is a need for further investigation of these parameters in future studies.

\section{CONCLUSION}

In conclusion, MVR with the preservation of the subvalvular apparatus improves clinical outcomes, such as long-term mortality, hospital length of stay, pneumonia, and bleeding. There is no significant difference in the incidence of stroke, renal failure, and ICU length of stay.

\section{REFERENCES}

Alizadeh-Ghavidel A, Mirmesdagh Y, Sharifi M, Sadeghpour A, Nakhaeizadeh R, Omrani G. 2013. The Impact of Sub-valvular Apparatus Preservation on Prosthetic Valve Dysfunction During Mitral Valve Replacement. Res Cardiovasc Med. Feb;2(1):55-61.

Athanasiou T, Chow A, Rao C, Aziz O, Siannis F, Ali A, Darzi A, Wells F. 2008. Preservation of the mitral valve apparatus: evidence synthesis and critical reappraisal of surgical techniques. Eur J Cardiothorac Surg. Mar;33(3):391-401.

Chan V, Ruel M, Mesana TG. 2011. Mitral valve replacement is a viable alternative to mitral valve repair for ischemic mitral regurgitation: a casematched study. Ann Thorac Surg Oct;92(4):1358-65.

Chen L, Chen B, Hao J, Wang X, Ma R, Cheng W, Qin C, Xiao Y. 2013. Complete preservation of the mitral valve apparatus during mitral valve replacement for rheumatic mitral regurgitation in patients with an enlarged left ventricular chamber. Heart Surg Forum. 16(3):E137-43.

Chowdhury UK, Kumar AS, Airan B, Mittal D, Subramaniam KG, Prakash R et al. 2005. Mitral valve replacement with and without chordal preservation in a rheumatic population: serial echocardiographic assessment of left ventricular size and function. Ann Thorac Surg. Jun;79(6):1926-33.

Cingöz F, Günay C, Kuralay E, Yildirim V, Kiliç S, Demirkiliç U. 2004. Both leaflet preservation during mitral valve replacement: modified anterior leaflet preservation technique. J Card Surg. Nov-Dec;19(6):528-34.

Condado JA, Vélez-Gimón. 2003. Catheter-based approach to mitral regurgitation. J Intervent Cardiol 16:523-34.

Cotogni P, Barbero C, Rinaldi M. 2015. Deep sternal wound infection after cardiac surgery: Evidences and controversies. World J Crit Care Med. Nov 4;4(4):265-73.

Coutinho GF, Bihun V, Correia PE, Antunes PE, Antunes MJ. 2015. Preservation of the subvalvular apparatus during mitral valve replacement of rheumatic valves does not affect long-term survival. Eur J Cardiothorac Surg. Dec;48(6):861-7.

David TE, Uden DE, Strauss HD. 1983. The importance of the mitral apparatus in left ventricular function after correction of mitral regurgitation. Circulation. 68(3 Pt 2):II76-82.

Ellis SG, Whitlow PL, Raymond RE, Schneider JP. 2002. Impact of mitral regurgitation on long-term survival after percutaneous coronary intervention. Am J Cardiol 89:3158.

García-Fuster R, Estevez V, Gil O, Cánovas S, Martínez-Leon J. 2008. Mitral valve replacement in rheumatic patients: effects of chordal preservation. Ann Thorac Surg Aug;86(2):472-81.

García-Fuster R, Vázquez A, Peláez AG, Martín E, Cánovas S, Gil O, Hornero F, Martínez-León J. 2011. Factors for development of late significant tricuspid regurgitation after mitral valve replacement: the impact of subvalvular preservation. Eur J Cardiothorac Surg Jun;39(6):866-74.

Grigioni F, Enriquez-Sarano M, Zehr KJ, Bailey KR, Tajik AJ. 2001. Ischemic mitral regurgitation: long-term outcome and prognostic implications with quantitative Doppler assessment. Circulation 103:1759-64. 3.

Hüseyin A, İbrahim; Yasin AY, Özge A; Cengiz K; Denyan M. 2013. Preservation of the Mitral Valve Apparatus: Bileaflet Versus Monoleaflet (Midterm Results). Turkiye Klinikleri Journal of Medical Sciences. 33 (2): p464.

Kaul TK, Ramsdale DR, Meek D, Mercer JL. 1992. Mitral valve replacement in patients with severe mitral regurgitation and impaired left ventricular function. Int J Cardiol May;35(2):169-79.

Kodavatiganti R. 2002. Intraoperative assessment of the mitral valve by transoesophageal echocardiography: an overview. Ann Card Anaest $5: 27-34$.

Kouchak F, Askarian M. 2012. Nosocomial infections: the definition criteria. Iran J Med Sci. Jun;37(2):72-3.

Lee EM, Shapiro LM, Wells FC. 1996. Importance of subvalvular preservation and early operation in mitral valve surgery. Circulation. Nov 1;94(9):2117-23.

Lillehei C. 1963. Value of preserving chordal integrity. Both experimental and clinical data. J Thorac Cardiovasc Surg. 46:494-5.

Lillehei CW, Levy MJ, Bonnabeau RC, Jr. 1964. Mitral Valve Replacement with Preservation of Papillary Muscles and Chordae Tendineae. J Thorac Cardiovasc Surg. 47:532-43.

Maganti K, Rigolin VH, Sarano ME, Bonow RO. 2010. Valvular heart disease: diagnosis and management. Mayo Clin Proc. May;85(5):483-500.

Miller DC. 2004. The three-dimensional geometry of the mitral valve: implications for surgical therapy. Proceedings of the 84th Annual Meeting of the American Association for Thoracic Surgery, Toronto, Ontario.

Muthialu N, Varma SK, Ramanathan S, Padmanabhan C, Rao KM, Srinivasan M. 2005. Effect of chordal preservation on left ventricular function. Asian Cardiovasc Thorac Ann Sep;13(3):233-7.

Natsuaki M, Itoh T, Tomita S, Furukawa K, Yoshikai M, Suda H, Ohteki $\mathrm{H}$ et al. 1996. Importance of preserving the mitral subvalvular apparatus in mitral valve replacement. Ann Thorac Surg Feb;61(2):585-90.

Osswald BR, Blackstone EH, Tochtermann U, Thomas G, Vahl CF, Hagl S. 1999. The meaning of early mortality after CABG. Eur J Cardiothorac Surg. Apr;15(4):401-7.

Ozdemir AC, Emrecan B, Baltalarli A. 2014. Bileaflet versus posteriorleaflet-only preservation in mitral valve replacement. Tex Heart Inst J. Apr 1;41(2):165-9.

Piérard LA, Lancellotti P. 2004. The role of ischemic mitral regurgitation in the pathogenesis of acute pulmonary edema. N Engl J Med 351:1627-34.

Reece TB, Tribble CG, Ellman PI, Maxey TS, Woodford RL, Dimeling GM et al. 2004. Mitral repair is superior to replacement when associated with coronary artery disease. Ann Surg. May;239(5):671-5; discussion $675-7$. 
Rossi A, Zoppini G, Benfari G, Geremia G, Bonapace S, Bonora E et al. 2017. Mitral Regurgitation and Increased Risk of All-Cause and Cardiovascular Mortality in Patients with Type 2 Diabetes. Am J Med. Jan;130(1):70-76.

Sakai K, Nakano S, Taniguchi K, Sakaki S, Hirata N, Shintani H et al. 1992. Global left ventricular performance and regional systolic function after suture annuloplasty for chronic mitral regurgitation. Circulation. Nov;86(5 Suppl):II39-45.

Solomon NA, Pranav SK, Naik D, Sukumaran S. 2006. Importance of preservation of chordal apparatus in mitral valve replacement. Expert Rev Cardiovasc Ther 4(2):253-61.

Starr A, Edwards ML. 1961. Mitral replacement: clinical experience with a ball-valve prosthesis. Ann Surg 154: 726-740).

Timala RB, Joshi D, Aryal M, Bhandari K, Singh Y, Sharma J. 2016. Effects of subvalvular apparatus preservation in mitral valve replacement among rheumatic patients: early and mid term follow up. Journal of Institute of Medicine 38 (2): 49-55.
Williams JB, Hernandez AF, Li S, Dokholyan RS, O'Brien SM, Smith PK, Ferguson TB, Peterson ED. 2011. Postoperative Inotrope and Vasopressor Use Following CABG: Outcome Data from the CAPS-Care Study. J Card Surg. Nov;26(6):572-8.

Yun KL, Sintek CF, Miller DC, Pfeffer TA, Kochamba GS, Khonsari S et al. 2002. Randomized trial comparing partial versus complete chordalsparing mitral valve replacement: effects on left ventricular volume and function. J Thorac Cardiovasc Surg. Apr;123(4):707-14.

Yun KL, Sintek CF, Miller DC, Schuyler GT, Fletcher AD, Pfeffer TA et al. 1999. Randomized trial of partial versus complete chordal preservation methods of mitral valve replacement: A preliminary report. Circulation. Nov 9;100(19 Suppl):II90-4.

Zakai SB, Khan SU, Rabbi F, Tasneem H. 2009. Effects of mitral valve replacement with and without chordal preservation on cardiac function: early and mid-term results. J Ayub Med Coll Abbottabad. Jan-Mar;22(1):91-6. 